\title{
Topographic amnesia: spatial memory disorder, perceptual dysfunction, or category specific semantic memory impairment?
}

\author{
Rosaleen A McCarthy, Jonathan J Evans, John R Hodges
}

\begin{abstract}
A 60 year old patient, SE, who presented with a severe difficulty in finding his way around previously familiar environments and a mild prosopagnosia is described. SE had herpes simplex encephalitis resulting in selective right temporal lobe damage. He showed normal spatial learning, but was severely impaired in his ability to recognise pictures of buildings and landmarks. The disorder was not confined to the visual modality, but rather involved a loss of knowledge about famous buildings or landmarks when tested from their spoken name. SE was contrasted with a more severely prosopagnosic patient, PHD, who showed normal ability to recognise buildings and landmarks, indicating that recognition of people dissociates from recognition of buildings/ landmarks. It is concluded that SE's failure of place knowledge represents a category specific supramodal semantic memory impairment.
\end{abstract}

(F Neurol Neurosurg Psychiatry 1996;60:318-325)

Keywords: topographic amnesia; spatial memory disorder; perceptual dysfunction; category specific supramodal semantic memory impairment

Topographical amnesia is a disorder of finding one's way around familiar environments and in learning to navigate in new environments. Two major subdivisions of the disorder have been postulated-namely, a primary disorder of spatial memory and a failure to recognise places. ${ }^{1}$ To date, however, there have been few descriptions of patients with topographic amnesia, and a very limited number on which detailed neuropsychological analysis has been carried out.

DeRenzi et al described a patient who, after a right parietotemporal stroke, showed extreme difficulty in finding her way about both new and previously familiar environments. Her ability to recognise places was not formally tested, although it is reported that she had no difficulty in recognising visual objects and people from their faces. She also had adequate space perception, and performed normally on a series of verbal and visual memory tasks. She was, however, extremely impaired on learning a route through a visual maze, failing to learn after 275 trials. She is, therefore, representative of topographic amnesic patients with a primary disorder of spatial memory. By contrast, Pallis ${ }^{3}$ described a patient whose spatial memory was good, such that he was able to describe on a map of Cardiff the appropriate route from the hospital to the railway station, but was at a loss when asked to find his way when in the city. He reported that places looked unfamiliar to him. Whitely and Warrington $^{4}$ also described a topographic amnesic patient who was poor at identifying familiar buildings and was impaired on a memory test for buildings although relatively normal on other visual memory tests. Spatial memory was not formally tested, although Whitely and Warrington suggest that it was normal on the basis of the patient's ability to successfully find his way around using maps and verbal instructions.

Many of the reported cases of topographic disorientation resulting from a place agnosia also show some degree of prosopagnosia. ${ }^{5}$ This raises the question of whether this finding is an anatomical coincidence (places and faces are processed by separate cognitive systems, but systems which are anatomically close), or whether it is a result of the fact that a single cognitive system subserves face and place processing. Prosopagnosic patients have often been reported to be equally impaired at recognising other unique exemplars of categories of objects. For example, the patient extensively documented by DeHann and coworkers ${ }^{67}$ had difficulties recognising specific flowers and makes of car. However, the prosopagnosia literature has tentatively moved in the direction of the conclusion that faces are "special," in the sense that they may be highly selectively impaired. There are examples of patients who are impaired at recognising faces, but unimpaired at recognising unique exemplars of other classes of visual stimuli, ${ }^{89}$ with the double dissociation provided by patients who are able to recognise faces, but impaired on recognising other visual stimuli (such as the farmer who could recognise his family, but not his cows. ${ }^{10}$ ) Fewer case reports in the prosopagnosia literature describe associated topographic amnesia, and this has rarely been assessed in any detail.

We report a patient, SE, with topographic amnesia and mild prosopagnosia, who has had detailed neuropsychological assessment, including tests of both his spatial memory and his place recognition skills. The results suggest that his deficit is in place recognition. In this case, however, the disorder is not confined to a visual deficit, but rather seems to involve some loss of semantic knowledge for places. We also explore the relation between prosopagnosia 
Figure 1 MRI showing gross destruction of the right hippocampus, parahippocampal gyrus, temporal pole, and inferior and middle temporal gyri on the coronal T1 weighted $(A)$ and horizontal $T 2$ weighted (B) reconstructions of the $3 D$ SPGR sequences. On the left side there was a small area of damage involving the anterior amygdala and uncus (see arrows).

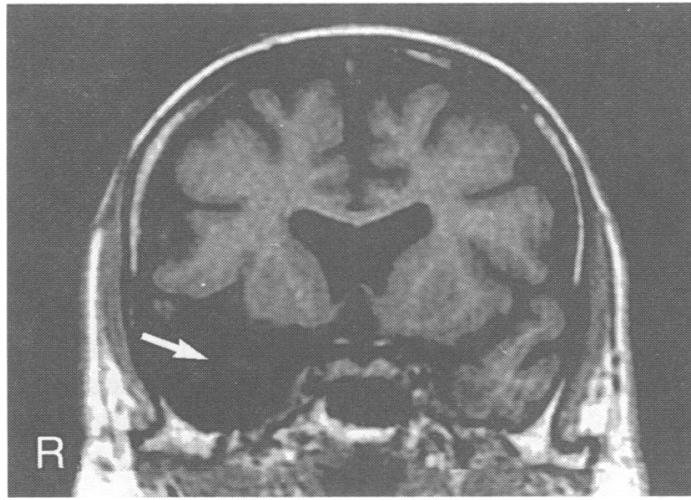

$A$

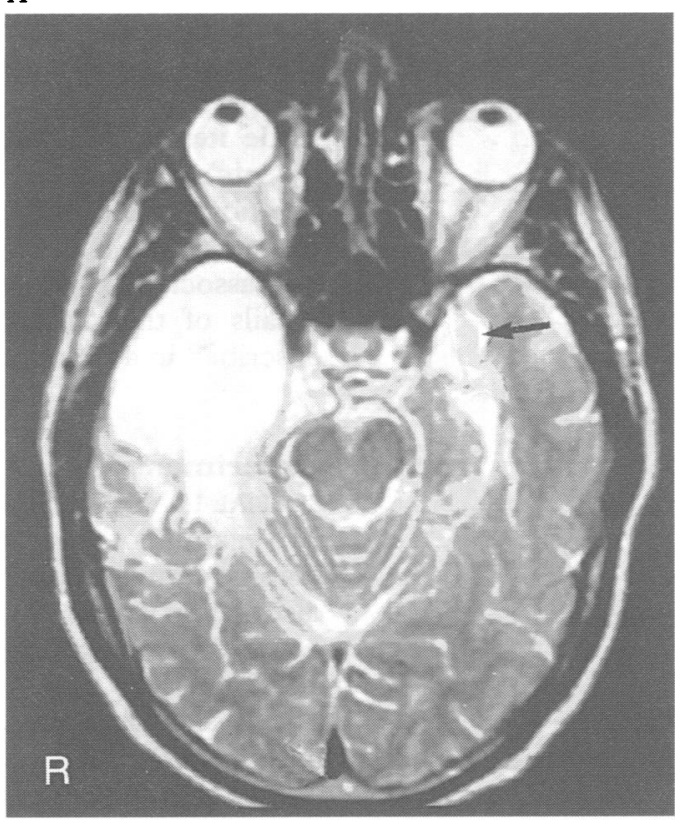

$B$

and place recognition deficits by comparing SE with another patient, PHD, who has a more severe prosopagnosia but normal recognition for places.

\section{Clinical history}

SE, a left handed ex-railwayman, was 60 when he came to our attention in December 1991. Five years previously he had been admitted to hospital in Great Yarmouth with a three day history of headache, nausea, pyrexia, confusion, and disorientation. A putative diagnosis of viral encephalitis due to herpes simplex was made and at that time CT showed low density areas in the right temporal lobe. He was discharged home from hospital three weeks later, described as being better oriented, but having memory impairment. When seen by us he complained of having great difficulty finding his way around places that were previously familiar to him, including his home town in which he had lived all of his life. On one occasion he was shown a photograph of a house in which he had lived for many years and was unable to identify it. Places which he knew should be familiar he described as appearing unfamiliar. He had managed to learn one route home from town and he always had to use this particular route, even if it meant going

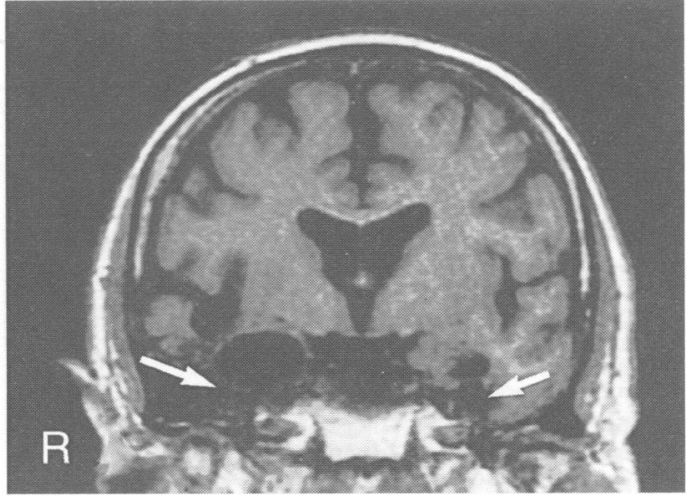

a long distance out of his way to attempt to get on to it. He also reported that he had difficulty recognising some less familiar people such as politicians and TV personalities, although most of his close family and friends were recognised. He had no major problems with past or current autobiographical details, his day to day (episodic) memory for ongoing events was good, he was capable of leading an independent life, and indeed maintains an active role within a number of local organisations.

Neurological examination confirmed the presence of severe bilateral anosmia; he was unable to detect or identify common odours used in clinical practice (coffee, oil of cloves, etc). The remainder of the bedside evaluation was normal: visual acuity $6 / 6$ bilaterally, no errors on the Ishihara colour charts, fields full, and pupils fully reactive. On bedside cognitive evaluation, he was fully oriented and alert, obtaining a score of $30 / 30$ on the mini mental state examination. ${ }^{11} \mathrm{His}$ speech was fluent and well articulated without paraphasic errors. Naming of common objects and repetition were flawless. He was able to retain a name and address after a filled delay and exhibited an excellent grasp of current and recent news events. There was no evidence of visuospatial or other basic perceptual deficits.

\section{Brain imaging}

Magnetic resonance imaging was carried out using axial multiecho and 3D SPGR sequences with coronal reconstructions. The T1 weighted sequence showed (fig 1A) gross destruction of the right temporal pole, uncus, hippocampus, parahippocampal gyrus, and inferior and middle temporal gyri to the level of the insula with compensatory dilation of the temporal horn of the right lateral ventricle. The left side was normal with the exception of a small region of high signal on the T2 weighted sequence in the region of the uncus and amygdala (fig 1B), with a corresponding low signal region on the coronal $\mathrm{T} 1$ images (fig 1A). Diencephalic and frontal lobe structures were normal.

\section{General cognitive functioning}

SE was assessed on a range of standard neuropsychological tests. Table 1 gives the results. $\mathrm{He}$ had well preserved general intellectual 
Table 1 SE's performance on standardised neuropsychological assessments

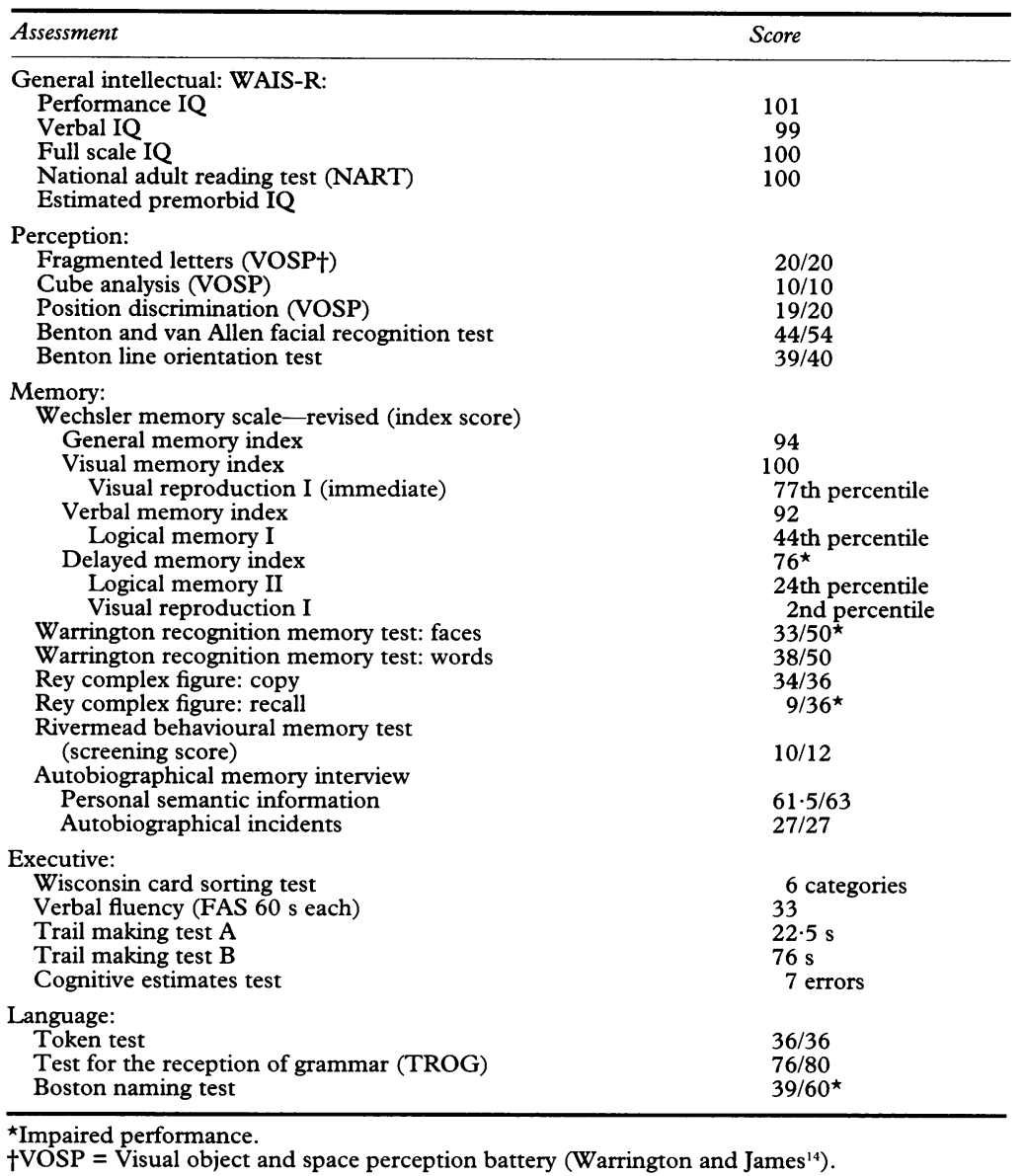

skills, with his current IQ, as measured by the Wechsler adult intelligence scale-revised ${ }^{12}$ being no different from his predicted premorbid IQ, based on his performance on the national adult reading test. ${ }^{13} \mathrm{He}$ also had satisfactory perceptual, language, and executive functioning. His performance on memory tests showed satisfactory verbal, but impaired visual memory functioning. Although he scored in the normal range on the Rivermead behavioural memory test and his general memory index on the WMS-R was normal and commensurate with his IQ, SE showed impairment in delayed recall of visual information (for example, visual reproduction and Rey figure). To assess his semantic memory abilities we compared his performance on a battery of experimental tests previously described in detail ${ }^{15}$ to that of 25 age and IQ matched controls. ${ }^{16}$ On the category fluency test, his total scores for the number of correct exemplars generated from three living and three man made categories fell within the normal range (SE living total 52 (controls 58.3 (SD 12.2)), man made 51 (controls 55.5 (SD 8.5))). Likewise his performance on the naming to description subtest was within the normal range, although all his errors were with animals (SE 20/24; controls 22.4 (SD 1.3)). At the time the present set of experiments were conducted, his picture naming (SE 32/48; controls 43.5 (SD 2.3)) and word-picture matching (SE 43/48; controls 47·1 (SD 1·1)) fell outside the normal range suggesting that SE has a mild semantic disorder. This was supported by his mildly impaired performance on the pyramids and palm trees test ${ }^{17}$ of associative semantic knowledge. He obtained a score of $45 / 52$ where controls make less than three errors. On the Snodgrass and Vanderwart corpus of 260 line drawings, SE was able to name 75 of the 100 pictures of natural kinds (animals, fruit, and vegetables, etc) compared with 152 of the $160(96 \%)$ man made items (vehicles, furniture, tools, clothing, etc). Further investigation showed that, in addition to his problems with buildings and places, SE has a mild, but significant, deficit in his associative knowledge of animals and details of this aspect of his case have been described in a separate paper. ${ }^{18}$

\section{Experimental investigations}

SPATIAL LEARNING AND KNOWLEDGE

To examine the possibility that SE's topographic amnesia was the result of a primary disorder of spatial memory, we carried out a series of investigations of his spatial learning and knowledge.

\section{Supraspan learning}

On a Corsi block tapping task, SE had a spatial short-term memory span of five. To assess supraspan learning, two further steps were added and SE was able to learn the extended span in three trials, a performance considered to be within normal limits. ${ }^{19}$

\section{Maze learning}

SE was assessed on two maze learning tasks. One task involved learning a route through an array of blocks or "stepping stones", similar in form to that described by Milner, ${ }^{20}$ and the other involved discovering and remembering a route through a complex maze, similar in type to the Porteus mazes. ${ }^{21}$ With both tasks, once the routes had been learned, the mazes were systematically rotated to investigate whether SE's learning was orientation dependent. For both tasks his performance was compared with that of five age and sex matched controls (mean age 64.4 (SD 2.61)).

Maze 1 (stepping stones)-This task involved learning a 16 step route through a $6 \times 6$ array of blocks or "stepping stones". Subjects were required to discover the route (involving either

Table 2 Performance (trials to criterion) of SE and controls on the stepping stone maze test

\begin{tabular}{|c|c|c|c|c|}
\hline & $\begin{array}{l}\text { Maze } 1 \\
\text { Criterion }=3 \text { correct }\end{array}$ & $\begin{array}{l}\text { Maze } 1 \\
\left(90^{\circ} \text { rotation) }\right. \\
\text { Criterion }=2 \text { correct }\end{array}$ & $\begin{array}{l}\text { Maze } 1 \\
\left(180^{\circ} \text { rotation }\right) \\
\text { Criterion }=2 \text { correct }\end{array}$ & $\begin{array}{l}\text { Maze } 2 \\
\text { Criterion }=1 \text { correct }\end{array}$ \\
\hline $\begin{array}{l}\text { SE } \\
\text { Controls }(n=5)\end{array}$ & $\begin{array}{l}8 \\
9 \cdot 0(4 \cdot 3)\end{array}$ & $\begin{array}{l}4 \\
6 \cdot 3(3 \cdot 3)\end{array}$ & $\begin{array}{l}2 \\
3 \cdot 3(2 \cdot 3)\end{array}$ & $\begin{array}{l}8 \\
5 \cdot 5(2 \cdot 4)\end{array}$ \\
\hline
\end{tabular}

Values for controls are mean (SE) 
A
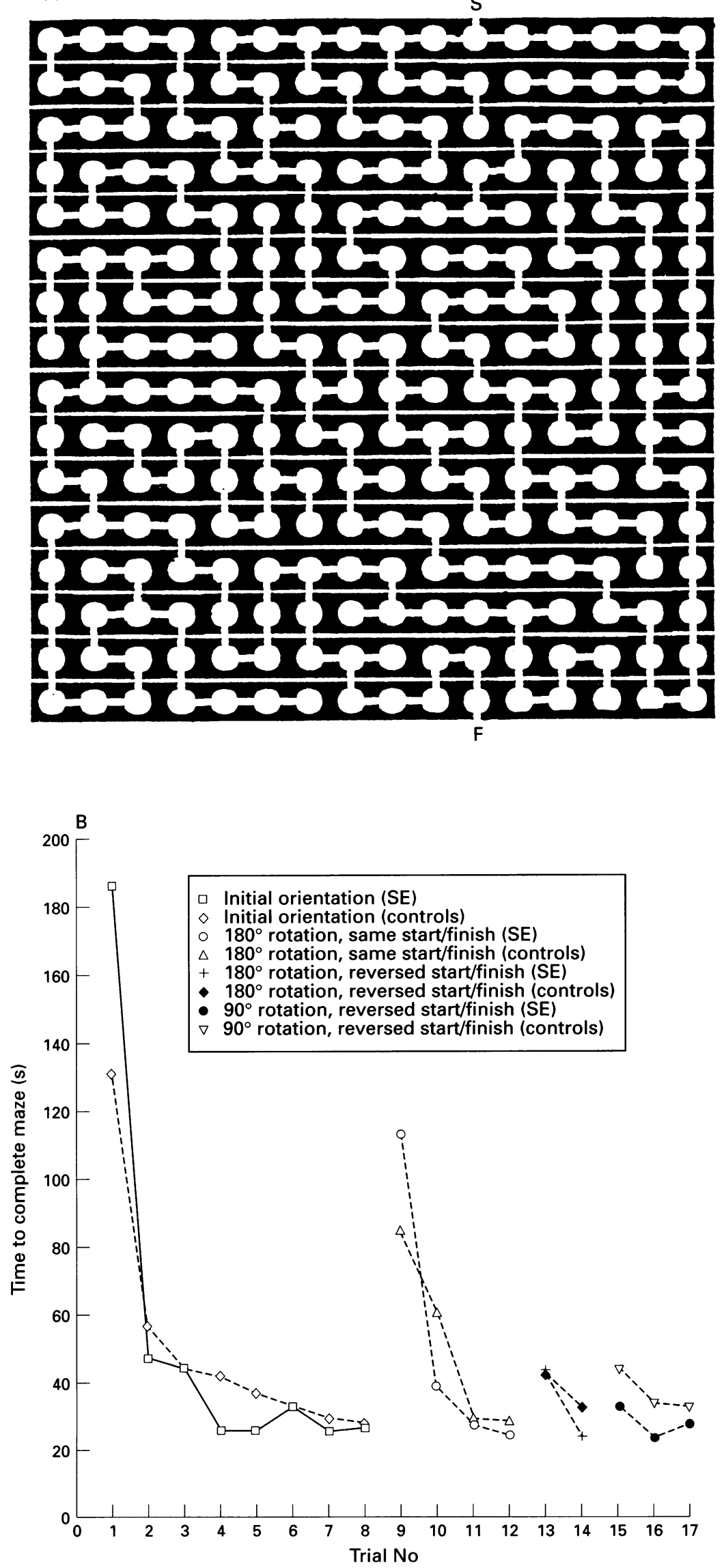

Figure 2(A) The complex labyrinth maze. (B) Performance of SE and controls on the complex labyrinth maze. vertical or horizontal, but not diagonal moves) through the maze by trial and error; when an error was made subjects were prompted immediately to find an alternative step. Trials continued until the route could be reproduced without error on three consecutive occasions. After three correct trials the maze was rotated 90 degrees and trials continued until a criterion of two consecutive error free trials was reached. A further 90 degree rotation followed and once again trials continued until a criterion of two consecutive error free trials was reached. Finally, a second maze was learnt and trials continued until error free performance was obtained.

Table 2 shows the performance of SE and controls on each of the mazes and shows that SE was essentially normal on this task, though he was a little slower to learn the second maze than the controls (possibly the result of proactive interference).

Maze 2-On this task subjects were presented with a complex labyrinth maze (fig $2 \mathrm{~A}$ ) and asked to find the path through the maze from start to finish. The time taken to do this was recorded. To assess learning, subjects were repeatedly re-presented with the same maze. Having reached a plateau in speed of completion, various manipulations were carried out including (a) rotating the original maze 180 degrees, but keeping the same start and finish positions, (b) rotating the original maze 180 degrees, reversing the original start and finish positions, and (c) rotating the original maze 90 degrees, reversing the original start and finish positions. Figure 2B shows SE's rapid learning of the original maze, evidenced by reduced times to completion, and also shows that the manipulations of orientation had little impact on speed of completion. His performance shows virtually no difference from the mean of the controls.

Locomotor route learning

SE was tested on a route within Addenbrooke's Hospital. The route, previously unfamiliar to SE, involved 10 decision points (go left, go right, or go straight on). The route was first demonstrated to $S E$ and after walking back to the beginning he was asked to retrace the route. Errors were noted and corrected when they happened. SE took four trials to learn the route successfully, making six errors across the four trials. After a 20 minute delay he was retested and was able to recall the route correctly. Five age matched control subjects (mean age 60.0 (SD 1.58)) were also tested on the route. Four of the subjects learned the route after only one trial and one subject made a single error on the first trial. All five recalled the route correctly after the 20 minute delay. It is clear that although this was a relatively simple route, SE was impaired compared with the controls. Nevertheless, given his self reports of problems with routes, we were surprised at his effective learning of the route. On discussing this with him it became apparent that he was relying on very specific verbal strategies to aid in the learning process (for example, "turn left at the physio- 
Figure 3 SE's drawing from memory of his home town.

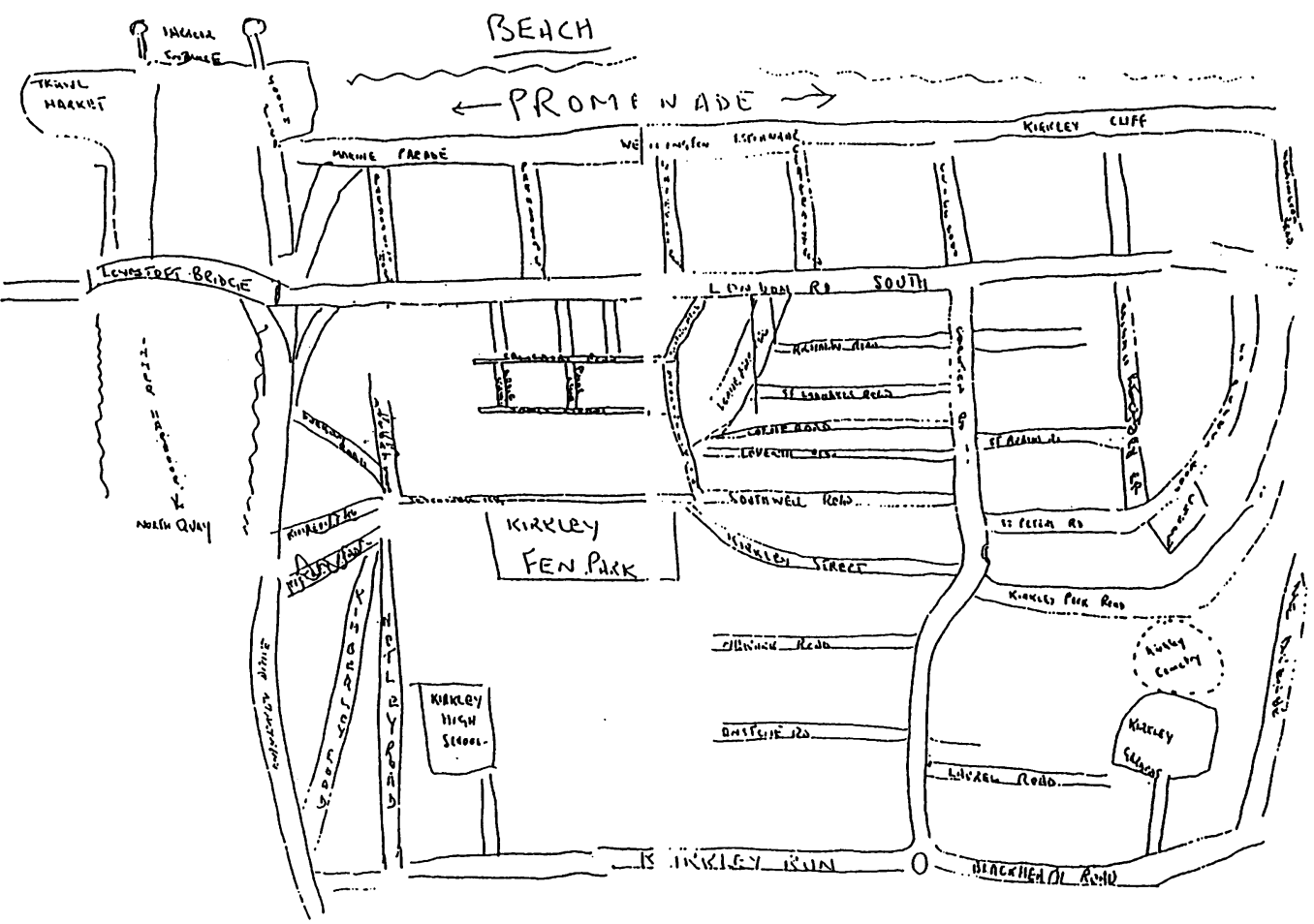

therapy sign, turn right when I see ward C2"). This approach, however, occasionally let him down; for example, on trial 1 he had used the strategy, "go past the doors and turn left where there is a man sitting down," which resulted in errors at stages five and six on trial 2 , when the man had moved! To contrast with the hospital route we also assessed SE on a route in the city centre of Cambridge. The route was chosen to have the same number of decision points as the hospital route and the same procedure was used. The result was a similar performance, SE learning the route after four trials, making a total of 10 errors, and successfully retracing the route after a 20 minute delay. Once again he relied on specific verbal strategies (usually street names) to help him navigate and his errors were almost always at decision points where there were no obvious street signs.

\section{Geographical knowledge}

SE was asked to draw a map of his home town, which he did very successfully (fig 3 ).

\section{Comment}

The results of the preceding investigations suggest that SE's spatial knowledge and learning are virtually normal, although we saw some evidence of his topographical navigation problems, as well as his use of compensatory strategies, on the locomotor routes. We moved on to investigate the possibility that SE's topographic disorientation was the result of an agnosia for familiar places. At the same time, we carried out parallel investigations into his difficulty with familiar faces to explore the potential relation between problems with faces and places. In this set of investigations we contrasted SE's performance with that of a more severely prosopagnosic patient. PHD, a 34 year old left handed man, was previously a trainee draughtsman. He sustained a severe head injury at the age of 18 and has experienced persisting problems with face recognition, recognition of animals, reading, and writing (with a pattern of surface dyslexia and dysgraphia) and episodic memory.

\section{PEOPLE AND PLACES}

Famous people

SE and PHD were shown photographs of 53 very famous people who had been prominent over the past four decades (politicians, TV and film stars, etc) and asked to provide the name of the person, or if unable to name the person, to provide specific identifying information. On another occasion SE and PHD were given the names of the famous people and asked to provide as much information about them as possible. In the second condition, and when identifying information was given by the patient rather than the name in the photograph condition, two independent raters assessed each response. A scoring criteria was adopted such that a response was scored as correct if the general occupation plus at least one other piece of correct information was given. For example, an answer "actor" or "sportsman" would not be sufficient, but "English actor" or "comedy actor" or "Sport-tennis player" or "football player" were all scored as correct. Agreement between the raters was almost $100 \%$; any disagreements were resolved by discussion. Control data were obtained from members of the MRC Applied Psychology Unit subject panel and staff of British Rail, Cambridge. In total, 37 subjects (mean age $49 \cdot 0$ (SD 17.6), range 20-82 years) were given the face identification task and 27 (mean age 53.7 (SD 15.4), range 
Figure 4 Performance of $S E$ and $P H D$ on the famous people and famous places tasks in which they are first asked to identify people and places from photographs and then asked to give information about people and places when provided with the name. Also shown is the mean performance (SD) of a healthy control group on the face and name identification tasks as well as the place identification from pictures and names and the performance of $S E$ 's wife on the places photograph task.

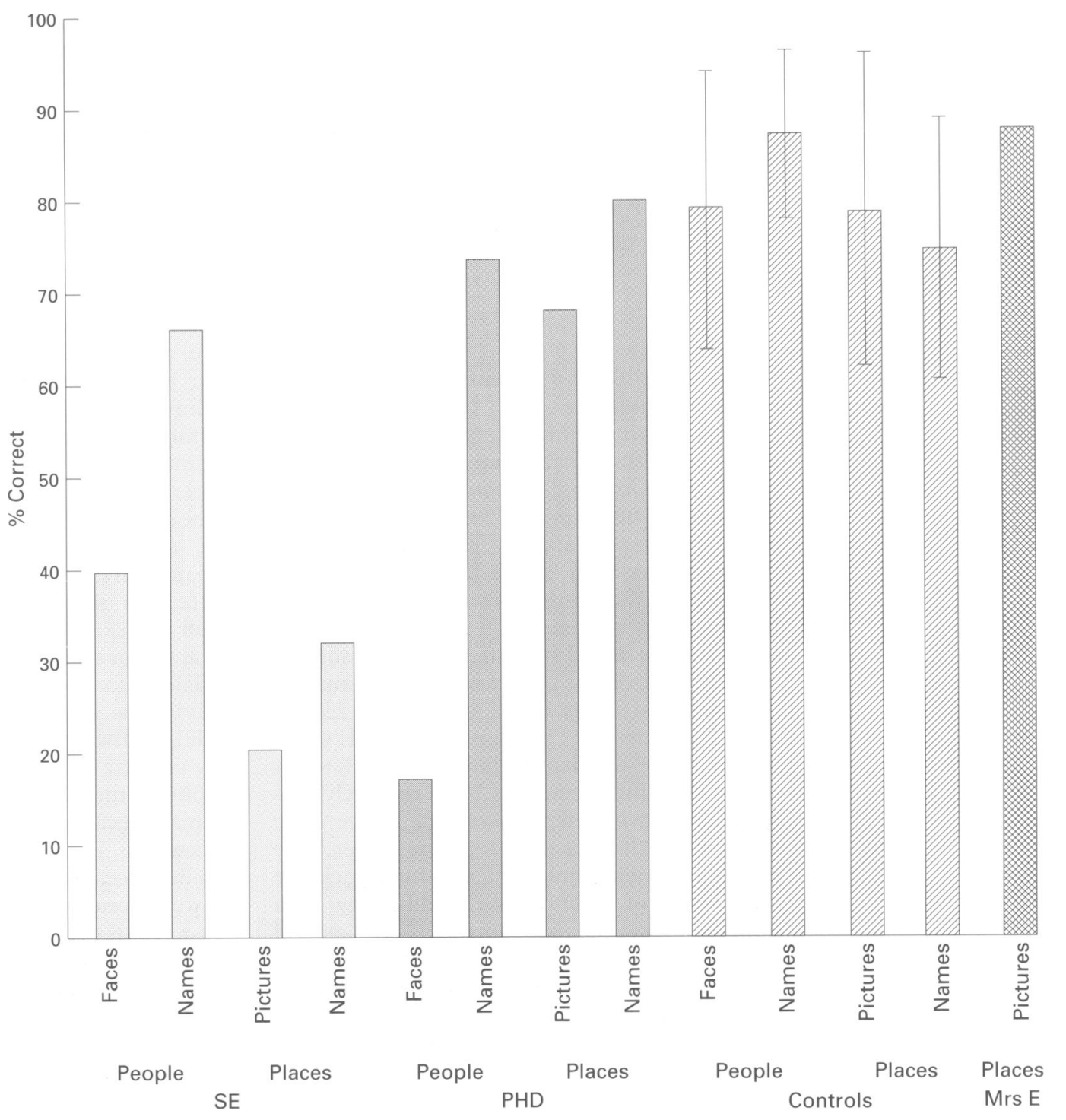

26-80 years) were given the name identification task. SE and PHD are considerably different in age, but because age did not correlate significantly with performance on either the face or name tasks, data from the whole control group are included. To compare the performance of the two patients across tasks their raw scores were converted to $\mathrm{z}$ scores.

The results, (fig 4) show that PHD was severely impaired (score $=16.98 \%, \quad z=$ $-4 \cdot 15)$, being well outside the range of normal controls in identifying famous faces, and SE is clearly poor (score $=39.62 \%, z=-2.64$ ), falling just below the range of normal controls $(43 \cdot 4 \%-98 \cdot 1 \%)$. On the identification from name task, PHD was well within the normal range (score $=73.58 \%, z=-1.51$ ), whereas SE's performance (score $=66.04 \%, \quad z=$ $-2.33)$ fell at the bottom of the range of normal controls $(62 \cdot 3 \%-100 \%)$.

\section{Famous Places}

SE and PHD were shown a set of photographs of 25 famous places (for example, the Statue of Liberty, Leaning Tower of Pisa, Pyramids, Eiffel Tower) and asked to provide the name or as much identifying information as possible. On another occasion they were provided with the name of each place and asked to provide as much information as possible about it. As with the famous faces task, in the second condition, and when identifying information was given by the patient rather than the name in the photograph condition, two raters rated each response to determine if it included sufficient information to clearly identify the famous building or landmark. Once again agreement between the raters was almost $100 \%$, with the few disagreements resolved by discussion. Control data were obtained from SE's wife (who was tested on the photographs) and age and education matched control subjects from the Applied Psychology Unit subject panel. Twenty nine subjects (mean age 56.79 (SD 16.11)) were asked to identify the places from photographs and a further 14 (mean age 43.79 (SD 17.76)) were asked to identify them from their names.

The results (fig 4) show that SE was severely impaired $(z=-3 \cdot 46)$ on recognising buildings or landmarks from photographs. For example, he thought that the Leaning Tower of Pisa was the Empire State Building, that Sydney Opera House was "Somewhere in Africa", and that Trafalgar Square was "Somewhere like Greece." When asked to 
identify places from their names he was somewhat better, but still significantly poorer than control subjects $(z=-3 \cdot 00)$. In this condition it was striking that he was often unable to provide any information about what a landmark looked like, even when information such as the location of the landmark was provided. By contrast, PHD was within the normal range for both the photograph and the name conditions.

\section{Discussion}

We have described a patient with a severe disorder of building and place recognition. Despite having normal spatial short term memory, normal maze learning, and excellent recall of pre-morbidly acquired spatial information, SE, nevertheless, had a grave disorder in finding his way around familiar places. Our investigations have established that SE's sensory and higher order perceptual skills were intact. He was normal on a range of visual tests that are failed by patients with disorders of visual sensory or perceptual processing and he performed at a normal level on tasks requiring him to identify common objects. SE's failure to name or identify familiar and famous places therefore seems to be a relatively isolated cognitive deficit, although as we have noted, and discuss in a separate paper, ${ }^{18}$ he had an additional mild deficit in his associative knowledge of animals. SE's difficulty with buildings and places appeared to extend beyond the visual recognition domain; we have documented a significant deficit in his ability to provide semantic information about places in response to their spoken names. In particular, his knowledge of the appearance of places seemed to be substantially impoverished.

These findings raise a number of issues regarding the organisation of those cognitive processes required for spatial orientation and navigation. Firstly, we shall consider the relative status of place recognition and spatial memory in topographic orientation; secondly, we shall discuss the possibility that failure to recognise buildings and places is part of a more pervasive information-processing deficit affecting the ability to identify exemplars within a class consisting of visually similar types. Finally, we shall discuss the implications of our findings for cognitive theories of memory organisation.

We have documented normal levels of performance on formal tests of short term and long-term spatial memory in a patient who is deficient in his recognition of landmarks. We were able to establish that SE could learn both "stepping stone" and "labyrinth" mazes effectively. His learning and memory for locomotor space were also explored on tests conducted in hospital and town environments. Although we found evidence of substantial learning, SE's learning in locomotor space did not seem to be entirely normal; he was over-reliant on verbally labelled cues and he made occasional errors in his selection of appropriate landmarks. We suggest, therefore, that SE's place recognition impairment extends into the anterograde domain: not only did he fail to identify previously familiar places, but he also had problems in coding those aspects of the environment that stand as cues to location. His preserved ability to code and process spatial information provided him with some topographic "tools". Knowledge of spatial routes and the availability of a mental map of the environment, even one as complex as that recalled by $S E$, are insufficient for normal navigation; knowing where you are at any one time and knowing when you have finished your journey requires the coding of places..$^{22}$ Failure at this level must be particularly disturbing in the context of an environment that is familiar. The fact that SE could learn simple routes in the hospital and in Cambridge demonstrates that verbal cues may compensate to some extent for place recognition impairments.

He was impaired on tasks involving the recall of visual forms after a delay. However, an anterograde visual memory deficit is not sufficient to account for his difficulties with finding his way around; many of his route finding difficulties involved places previously very familiar to him. Furthermore his autobiographical memory for facts and events was normal. Because SE showed moderate clinical difficulties in recognising and identifying familiar faces as well as in recognising places, we were concerned to establish whether there was a more pervasive visual information processing deficit that could account for both aspects of his case. Damasio and Damasio ${ }^{23}$ have proposed that prosopagnosia arises from impaired differentiation between visually similar tokens and in view of the common cooccurrence of prosopagnosia and topographic amnesia it seems plausible to suggest that places and faces are on a continuum of task difficulty. Our investigation of a patient with severe prosopagnosia served as a control for this set of possibilities. Despite grave difficulties in identifying faces (PHD's ability to identify famous people from their names was strikingly better than his face identification, as is the case in classic prosopagnosia), PHD was entirely normal in recognising places and buildings. We would argue that these findings are inconsistent with a simple visual information processing explanation of SE's disorder. A cross over dissociation of the type demonstrated here (although not a strong double dissociation in view of SE's mild impairment on the famous faces test) indicates that faces and places cannot lie on a single continuum of task difficulty. ${ }^{24} 25$

Further evidence against the visual information processing hypothesis can be drawn from the finding that SE's deficit extended to include impoverished knowledge of the spoken names of famous places. To the best of our knowledge, SE is the first documented case of a concordant verbal and visual deficit in the knowledge of buildings and landmarks. Previous cases of "building agnosia" have typically been assumed to have a primary failure in processing visual information, rather than a 
disorder which affects their conceptual knowledge (indeed the very notion of an agnosic contribution to topographic disorders arose in the context of differentiating impairments of perceptual processing from disorders of memory) ${ }^{1}$ The evidence for a "supramodal" deficit in SE suggests that his disorder arises centrally, beyond information detection, parsing, and perceptual organisation. We suggest that it implicates his semantic memory for buildings and landmarks.

It is now widely recognised that disorders of semantic knowledge can implicate specific categories of information. ${ }^{26}$ Impaired knowledge of "buildings" or "places" may therefore constitute an additional example of category specific semantic breakdown. Indeed, knowledge of places seems to be a particularly coherent category of knowledge-and one which may extend to infrahuman species. In this context, reports of "place sensitive" cells in the hippocampus of rats and monkeys are clearly relevant. ${ }^{27}$ If SE's deficit is to be conceptualised in these terms, then the asymmetry of his pathology raises the interesting possibility that the processing of landmarks as meaningful entities may be mediated via the non-dominant hemisphere. For most documented cases of semantic impairment, the lesion locus has consistently (although not exclusively) implicated the dominant or left temporal lobe (for reviews see $\mathrm{McCarthy}$ and Warrington ${ }^{25}$ and Patterson and Hodges ${ }^{28}$ ). However, Ellis et al ${ }^{29}$ described a patient who had undergone a right anterior lobectomy for long standing epilepsy and who had a semantic memory disorder affecting knowledge of buildings, people, and famous animals and, more recently, Evans et $a l^{30}$ described a patient with focal atrophy of the right temporal lobe who was initially prosopagnosic and progressed to have a more general loss of semantic knowledge of people. Although SE's lesion primarily involved the right temporal lobe and hippocampus, his left handedness complicates any interpretation of cerebral asymmetry. It would seem plausible, however, for the storage and processing of place knowledge to be closely linked with perceptual and spatial skills that are dependent on right hemispheric function. Further case studies may help to establish whether cognitive systems concerned with processing information relating to environmental landmarks are unusual in their dependence on the right hemisphere.

We are grateful to John Pilling for making the original referral and the patients and their families for their continuing assistance. We also thank SE and PHD for giving us permission to
use their initials in this paper. R A McC's work was partially supported by a grant from the Leverhulme Trust to Kings
College, Cambridge. We would also like to thank staff of British Rail, Cambridge, who gave their time to provide control data in this study, and two anonymous referees for their helpful comments on earlier versions of this paper.

1 Paterson A, Zangwill OL. A case of topographic disorientation associated with a unilateral cerebral lesion. Brain 1945;68:188-211.

2 DeRenzi E, Faglioni P, Villa P. Topographical amnesia. $\mathcal{f}$ Neurol Neurosurg Psychiatry 1977;40:498-505.

3 Pallis CA. Impaired identification of faces and places with agnosia for colours. Report of a case due to cerebral agnosia for colours. Report of a case due to cerebral
embolism. $f$ Neurol, Neurosurg Psychiatry 1955;18: embolism.

4 Whitely AM, Warrington EK. Selective impairment of topographical memory: a single case study. $\mathcal{F}$ Neurol Neurosurg Psychiatry 1978;41:575-8.

5 Grusser OJ, Landis T. Visual agnosias and other disturbances of visual perception and cognition. Basingstoke: Macmillan, 1991.

6 DeHaan EHF, Young AW, Newcombe F. Faces interfere with name classification in a prosopagnosic patient. Cortex 1987;23:309-16.

7 DeHaan EHF, Young AW, Newcombe F. Covert and overt recognition in prosopagnosia. Brain 1991;114:2575-91.

8 Bruyer R, Leterre C, Seron X, Feyereisen P, Strypstein E, Pierrard E, Rectem D. A case of prospagnosia with some preserved covert remembrance of familiar faces. Brain preserved covert rem

9 DeRenzi E. Current issues in prosopagnosia. In Ellis HD, Jeeves MA, Newcombe KF, Young AW, eds. Aspects of face processing. Dordrecht, Holland: Martinus, Nijhoff, 1986.

10 Assal G, Faure C, Anderes JP. Non-reconnaissance d'animaux familiers chez un paysan: zooagnisie ou prosopagnosie pour les animaux. Rev Neurol (Paris) 1984;140: 580-4.

11 Folstein MF, Folstein SE, McHugh PR, Mini-mental state: a practical method of grading the cognitive state of patients for the clinician. $\mathcal{F}$ Psychiatric Res 1975;12: patients

12 Wechsler D. Manual for the Wechsler adult intelligence scalerevised. New York: Psychological Corporation, 1981

13 Nelson H. National adult reading test. 2nd ed. Windsor, Berkshire: NFER-Nelson, 1991 .

14 Warrington EK, James M. Visual object and space perception battery. Flempton: Thames Valley Test Company, 1991.

15 Hodges JR, Salmon DP, Butters N. Semantic memory impairment in Alzheimer's disease: failure of access or degraded knowledge? Neuropsychologia 1992;30:301-14.

16 Hodges JR, Patterson K, Oxbury S, Funnell E. Semantic dementia: progressive fluent aphasia with temporal lobe atrophy. Brain 1992;115:1783-806.

17 Howard D, Patterson K. Pyramids and palm trees test. Flempton: Thames Valley Test Company, 1992.

18 Laws KR, Evans JJ, Hodges JR, McCarthy RA. Naming without knowing and appearance without associations: evidence for constructive processes in semantic memory. evidence for constructive
Memory 1995;3:409-33.

19 Hodges JR, Oxbury S. Persistent memory impairment following transient global amnesia. 7 Clin Exp Neuropsychol 1990;12:904-20.

20 Milner B. Visually guided maze learning in man: effects of bitemporal hippocampal, bilateral frontal and unilateral cerebral lesions. Neuropsychologia 1965;3:317-338.

21 Porteus SD. Porteus maze test. Fifty years application. Palo Alto: Pacific Books, 1965.

22 O'Keefe J, Nadel L. The Hippocampus as a cognitive map. Oxford: Clarendon Press, 1978.

23 Damasio AR, Damasio H. Face agnosia and the neural substrates of memory. Ann Rev Neurosci 1990;13:89-109.

24 Shallice T. From neuropsychology to mental structure. Cambridge: CUP, 1988.

25 McCarthy RA, Warrington EK. Cognitive neuropsychology: $a$ clinical introduction. London: Academic Press, 1990.

26 McCarthy RA, Warrington EK. The impairment of semanMcCarthy RA, Warrington EK. The impairment of se
tic memory. Philos Proc $R$ Soc Biol 1995;346:89-96.

27 O'Keefe J, Speakman A. Single unit activity in rat hippocampus during a spatial memory task. Exp Brain Res 1987;68:1-27.

28 Patterson K, Hodges JR. Disorders of semantic memory. In Baddeley AD, Wilson BA, Watts FN, eds. Handbook of memory disorders. Chichester: John Wiley, 1995:167-87.

29 Ellis AW, Young AW, Critchley EMR. Loss of memory for people following temporal lobe damage. Brain 1989;112: people follo $1469-83$.

30 Evans JJ, Heggs AJ, Antoun N, Hodges JR. Progressive prosopagnosia associated with selective right temporal lobe atrophy: a new syndrome? Brain 1995;118:1-13. 